made by fishes of the genus Therapon, as described by Dr. Hardenberg in a recent paper (Zöol. Anz., 108 ; 1934). The other sounds mentioned by Capt. Jansen have also been heard by Dr. Hardenberg, though less frequently, and once, when in the Java Sea, he heard sounds as if made by silver bells. Their origin is still unknown, but he supposes that they are also made by animals.

\section{American Society for Testing Materials}

IT is a great help to industry to have standard specifications for the materials used in commerce, and to have methods of testing to find out whether the materials offered for sale come up to the standard or not. In Great Britain the British Standards Institution (B.S.I.) of 28 Victoria Street, S.W.1, publishes standard specifications and gives also the methods of testing. These have been passed by committees consisting of engineers, manufacturers, Government officials and all interested in securing raw materials or finished products of the best quality. If experience shows that the methods used are ineffective, then the old committee meets again or another committee is formed and it brings out a revised specification. In the United States, the American Society for Testing Materials (A.S.T.M.) performs similar functions. The Proceedings of this Society are issued annually, and give reports by committees and the 'tentative' standards adopted. Each of the annual volumes contains about 2,000 pages. In the 1934 volume such subjects as vapour lock of petrol, creep tests and data, soil testing methods, rubber raw materials, etc., are discussed. Twenty-one of the standards appearing in the 1933 "Book of Standards" have been revised or discontinued. Fourteen of them have been revised, five of them have been replaced by new tentative standards and two have been completely withdrawn. The new problems discussed will be found of interest by physicists, and open up new fields of research.

\section{Society of Public Analysts}

Ar the annual general meeting of the Society of Public Analysts held on March 6, Dr. Bernard Dyer gave an address embodying his reminiscences of the Society, from its inception to the present day. At the outset of his address, Dr. Dyer pointed out that the occasion was particularly appropriate, since it was the diamond jubilee of the Society, which held its first meeting in February, 1875, when Dr. Redwood was elected president. Much of the early work of the Society was concerned with food adulteration, which at that time was gross and widespread, although gradually analytical chemistry in general was brought within the scope, and in 1906 this was recognised when the title of the Society was enlarged to include analytical chemists other than public analysts. Several of the earlier presidents were well known as medical officers of health, who had also been appointed public analysts. Dr. Dyer also touched on the history of the Society in connexion with the Institute of Chemistry and the Government Laboratory, and laid stress upon the fact, that in spite of certain coolness and misunderstandings in earlier days, the most cordial relations have for many years existed between the Society and these bodies. The following officers were elected for 1935 : President, Mr. John Evans; Vice-Presidents, Messrs. L. H. Lampitt, S. E. Melling, A. More, W. H. Roberts ; Honorary Treasurer, Mr. E. B. Hughes; Honorary Secretary, Mr. G. Roche Lynch.

\section{Hydrogen Cooling}

The losses due to air friction when machines are rotating is often an appreciable fraction of the total working losses. The losses can be considerably redueed by running the machines in hydrogen. As the thermal conductivity of hydrogen is much greater than that of air, the temperature rise of the machine is further reduced and so it can be run at a heavier load and can therefore be rated as a more powerful machine. In the Electrician of March 1, there is a description of a 30,000 kilovolt ampere synchronous condenser which has been built for the French Midi Railway. The outer casing is built up of steel plates bolted together and designed to withstand the force of any internal explosion which might occur owing to a mixture of hydrogen and air. The machine is started by a special type of transformer which only takes a quarter of full load current. Tests carried out on the machine with hydrogen and air as cooling media show that the heating of the machine with hydrogen-cooling was thirty per cent less than when it was run in air.

\section{The Murdoch Trust}

THERE has been in existence for a number of years a most admirable trust, known as the Murdoch Trust, for the benefit of indigent bachelors and widowers who have done good work for science and have fallen on less prosperous days. Few people seem to be aware of the existence of this Trust or of its beneficent purpose, though a modest advertisement occasionally appears, as, for example, in NATURE of March 2, p. lxvi, inviting applications for donations or pensions from it. We gladly direct attention to the aid thus available to persons who have promoted or helped the advancement of any branch of science and are in need. The Trusteos welcome applications from scientific workers eligible for assistance from the funds they have available. Particulars can be obtained from Messrs. Shepherd and Wedderburn, 16 Charlotte Street, Edinburgh.

\section{Ibero-Americana Oceanographical Conference}

THE Ibero-Americana Oceanographical Conference was to have met at Madrid in October last, but it was found necessary to alter the date, and the assembly of the delegates was postponed until the latter part of April 1935. As at present arranged, the Conference will hold its meetings partly in Madrid and partly in Malaga. Invitations to attend were sent to the Governments of the various North and South American States and to the Governments of those countries having territories in America. It is understood that the Conference will discuss 